\title{
Erratum to: Chromosome doubling to overcome the chrysanthemum cross barrier based on insight from transcriptomic and proteomic analyses
}

Fengjiao Zhang ${ }^{1,2}$, Lichun Hua ${ }^{1}$, Jiangsong Fei ${ }^{1}$, Fan Wang ${ }^{1}$, Yuan Liao ${ }^{1}$, Weimin Fang ${ }^{1}$, Fadi Chen ${ }^{1}$ and Nianjun Teng ${ }^{1,2^{*}}$

\section{Erratum}

Unfortunately, the original version of this article [1] contained an error. The Figure legends for Figs. 3, 4, 5 and 6 are incorrect. The correct version of Figs. 3, 4, 5 and 6 can be found below.

The correct match is as follows:

\section{Reference}

1. Zhang F, et al. Chromosome doubling to overcome the chrysanthemum

cross barrier based on insight from transcriptomic and proteomic analyses.

BMC Genomics. 2016;17:585. doi:10.1186/s12864-016-2939-0.

* Correspondence: nianjunteng@163.com; njteng@njau.edu.cn

${ }^{1}$ College of Horticulture, Nanjing Agricultural University, Nanjing 210095, China

${ }^{2}$ Jiangsu Province Engineering Lab for Modern Facility Agriculture

Technology and Equipment, Nanjing 210095, China

Submit your next manuscript to BioMed Central and we will help you at every step:

- We accept pre-submission inquiries

- Our selector tool helps you to find the most relevant journal

- We provide round the clock customer support

- Convenient online submission

- Thorough peer review

- Inclusion in PubMed and all major indexing services

- Maximum visibility for your research

Submit your manuscript at

www.biomedcentral.com/submit 


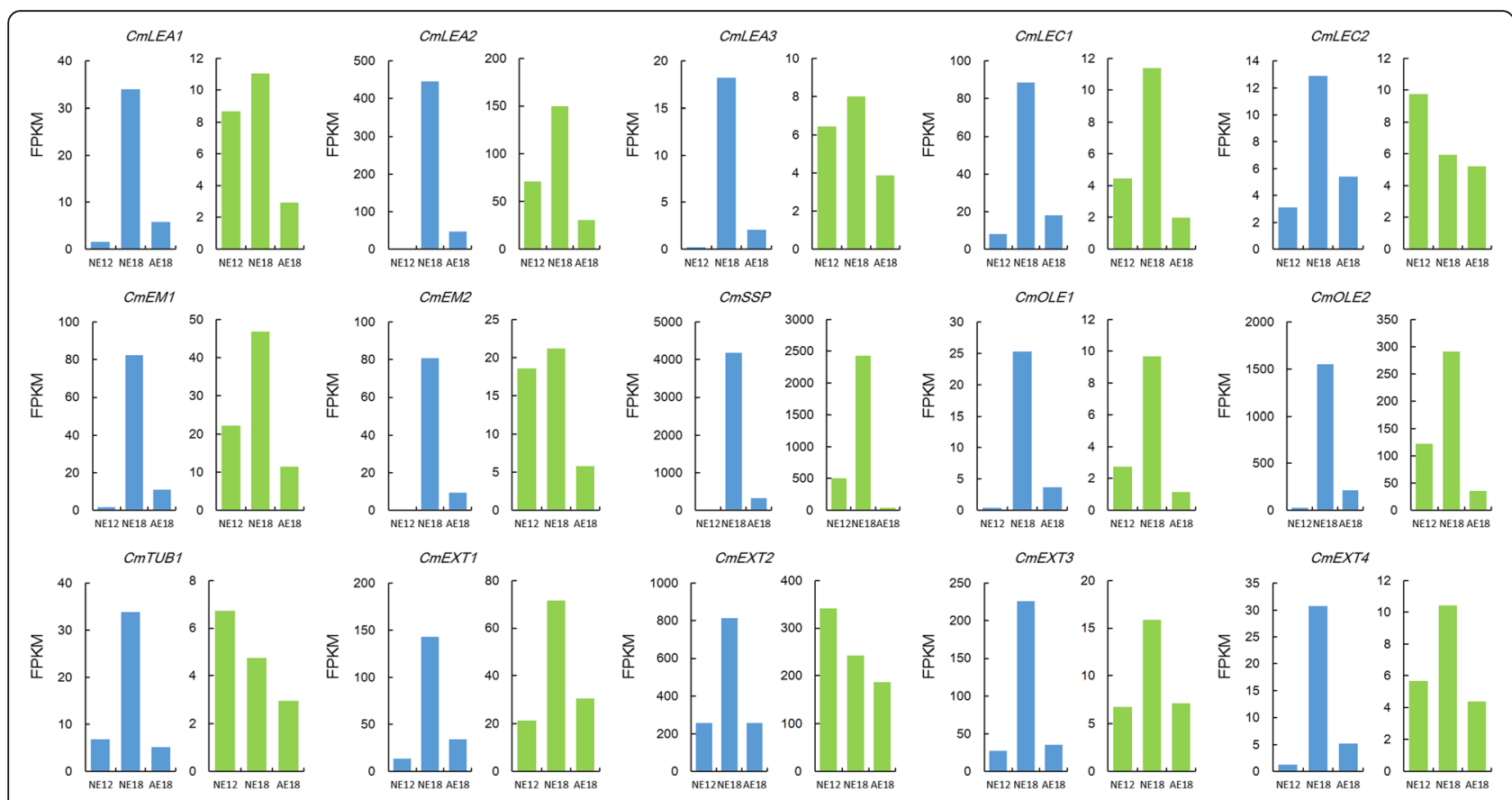

Fig. 3 The expression patterns of DEGs in two transcriptome libraries. Blue columns represent the cross C. morifolium $\times$ tetraploid C. nankingense, and green columns represent the cross C. morifolium $\times$ diploid C. nankingense

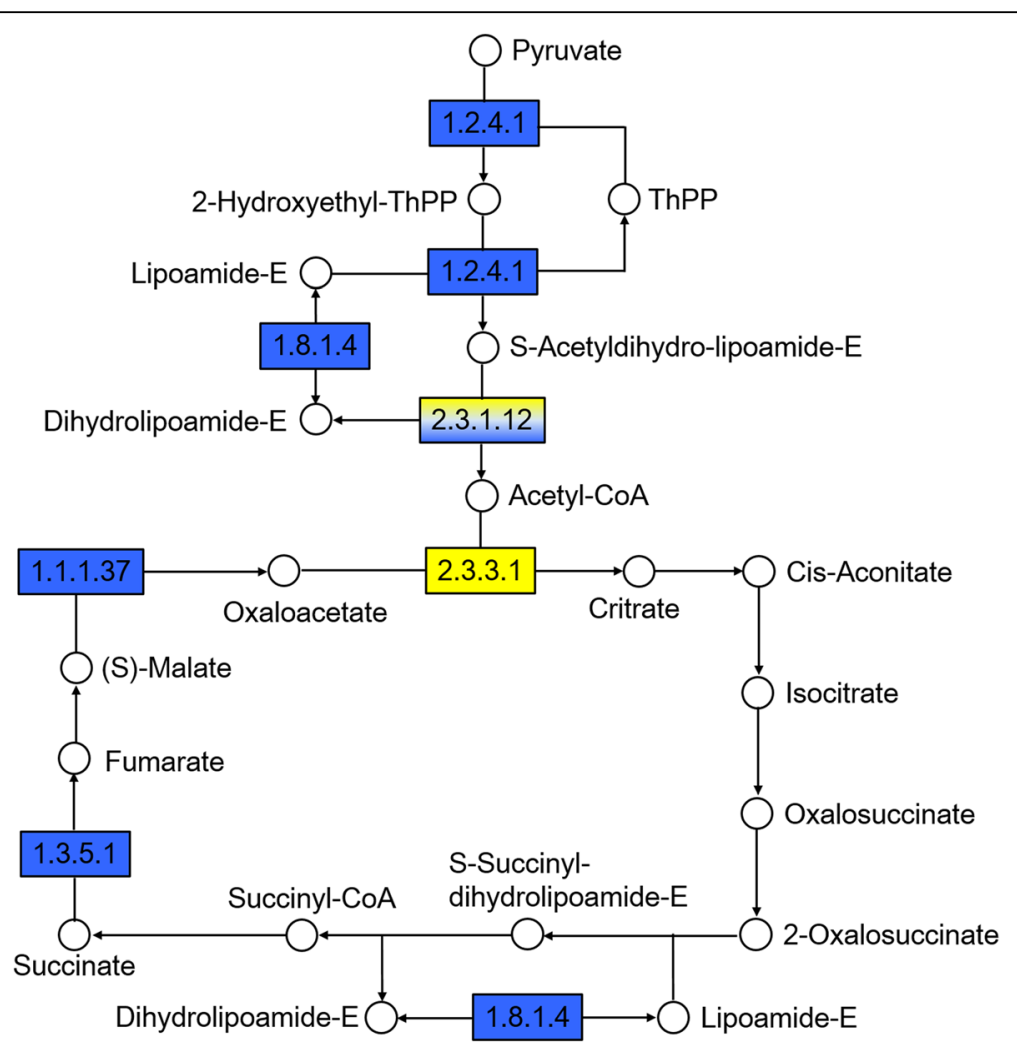

Fig. 4 Analysis of the tricarboxylic acid (TCA) cycle pathway in normal and abnormal embryos 18 DAP in the cross C. morifolium $\times$ tetraploid C. nankingense. The map displays selected steps from the KEGG pathway ko00020 'Citrate cycle (TCA cycle)'. Yellow indicates higher relative levels and blue indicates lower levels in AE18. Enzymes are given as EC numbers: 1.2.4.1, pyruvate dehydrogenase; 1.8.1.4, dihydrolipoamide dehydrogenase; 2.3.1.12, dihydrolipoamide acetyltransferase; 2.3.3.1, citrate synthase; 1.3.5.1, succinate dehydrogenase; and 1.1.1.37, malate dehydrogenase 


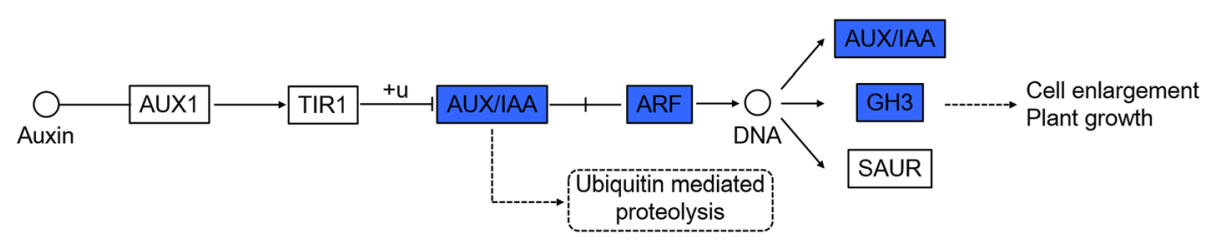

Fig. 5 Analysis of the pathway related to auxin signal transduction in normal and abnormal embryos 18 DAP in the cross C. morifolium $\times$ tetraploid C. nankingense. The map displays selected steps from the KEGG pathway ko04075 'Plant hormone signal transduction'. Blue indicates the lower expression level of genes in AE18

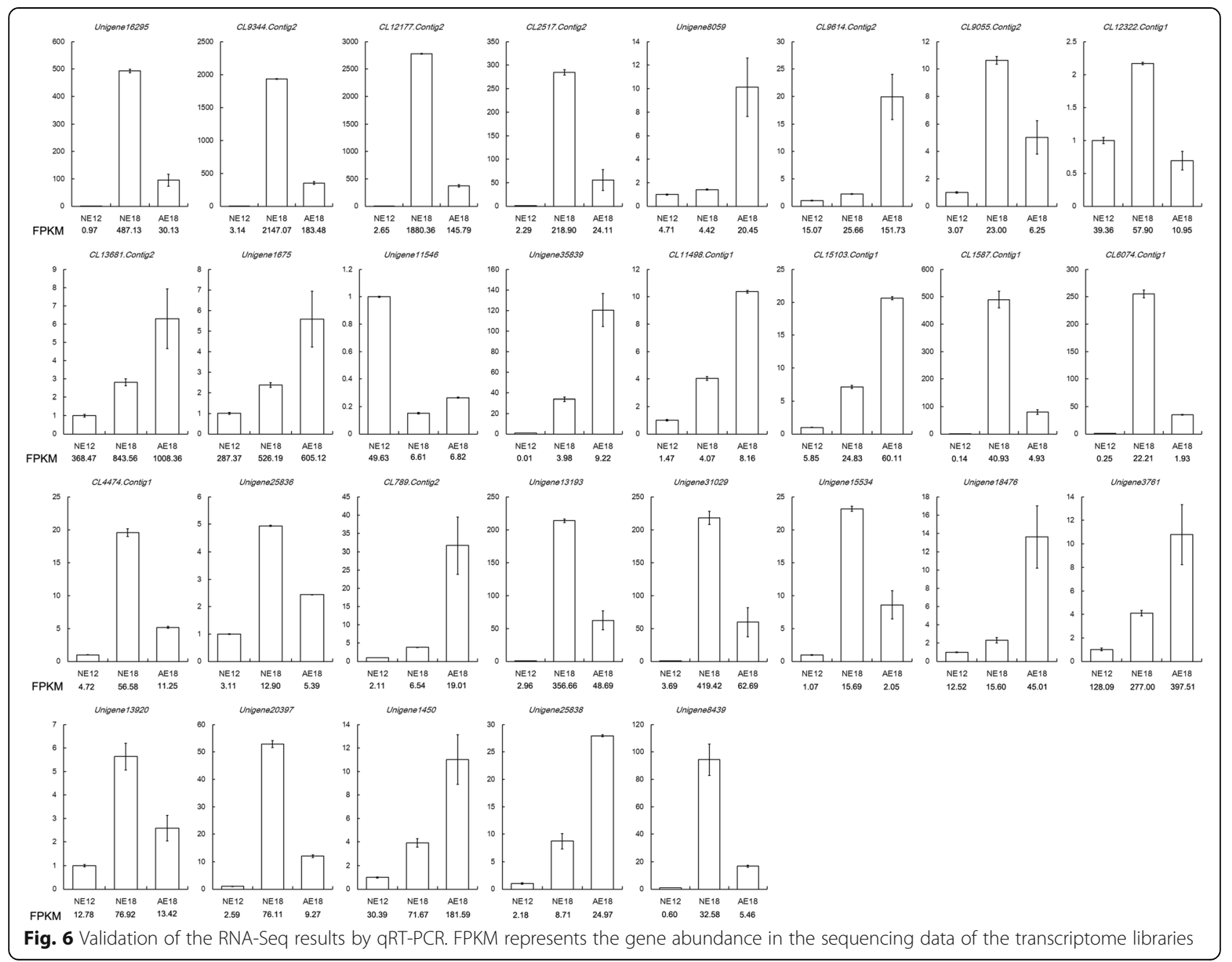

